\title{
Congenital idiopathic chylothorax in neonates: chemical pleurodesis with povidone-iodine (Betadine)
}

\author{
O Brissaud, L Desfrere, R Mohsen, M Fayon, J L Demarquez
}

Arch Dis Child Fetal Neonatal Ed 2003;88:F531-F533

Chylothorax is defined as an accumulation of chyle in the pleural space. This condition usually occurs after an operation, the congenital idiopathic form being rare $(1 / 15<$ thin $>000$ births). Recovery is observed within four to six weeks of diagnosis in most cases. Treatment is either conservative or surgical. Four cases are reported of congenital chylothorax (three idiopathic, one accompanied by diffuse lymphangectasia) managed by chemical pleurodesis (intrapleural injection of povidone-iodine). Tolerance was satisfactory: unaltered thyroid function in the three cases explored; one case of transient generalised oedema. Treatment was deemed successful in three of the four cases. One child died from renal failure (unrelated to the chemical pleurodesis). Pleurodesis by povidone-iodine appears to be well tolerated and may represent a good alternative to mechanical abrasion or surgery for congenital idiopathic chylothorax. Its use for refractory chylothorax may also decrease the morbidity related to prolonged hospital stay.



ongenital idiopathic chylothorax is the most common cause of pleural effusion in the neonatal period. ${ }^{1-4}$ Its prevalence is about $1 / 15<$ thin $>000$ births, and accounts for $8 \%$ of chylothoraces in children. ${ }^{5}$ The outcome is characterised by a perinatal mortality of $15-57 \% .{ }^{1346}$ If chylothorax is associated with hydrops fetalis, mortality can reach $98 \% .{ }^{1}$ Antenatal management consists of thoracocenteses or pleuroamniotic shunts ${ }^{1348}$ to prevent secondary pulmonary hypoplasia. ${ }^{13489}$ In the postnatal period, the classical management of the pleural effusion (in addition to the symptomatic treatment of the respiratory distress) can be either conservative or surgical (see the box)..$^{1-6}{ }^{10-12}$ Another recent conservative treatment is the use of a continuous infusion of somatostatin. ${ }^{13}$ Morbidity related to the management of congenital idiopathic chylothorax is high because there is a risk of nosocomial infections (low serum immunoglobulins, malnutrition, lymphopenia, long term central venous catheters, and chest tube drainage). It is thus important to develop methods than can decrease this morbidity and reduce hospital stay. Pleurodesis with a chemical agent in children has previously been described, ${ }^{2}$ but never with povidone-iodine (Betadine). We report on four cases of congenital chylothorax treated by a simple method-that is, povidone-iodine pleurodesis. All patients were recruited over a period of six months during the year 2000. Informed consent to perform the procedure was obtained from the children's parents.

\section{CASE REPORTS}

Table 1 gives the basic details of the four cases.

\section{Case 1}

A bilateral chylothorax was diagnosed in a female fetus during pregnancy. Bilateral pleuroamniotic tubes were inserted at 30 weeks because of compressive hydrothorax and maintained until birth at 31 weeks gestation. Her parents were unrelated, and chromosome analysis was normal. After birth, the chest tubes were removed with a good initial outcome. However, a right pleural effusion reappeared rapidly, requiring 26 pleural thoracocenteses up to day 53 (total volume $1250 \mathrm{ml}$ ), initially one a week, then two a week despite total parenteral nutrition. At day 53, a chest tube was inserted. Because of loculations, a larger tube was surgically inserted on day 65 when an intrapleural instillation of povidone-iodine (Betadine $4 \%$ scrub) was performed. The chest tube was finally removed on day 81 after complete recovery. The infant is healthy, without recurrence of the pleural effusion. Thyroid function tests were normal before and after treatment.

\section{Case 2}

A 2300 g, 35 week gestation female infant was born after a tocolysis failure. The parents were first cousins. Fetal hydrops was diagnosed at 34 weeks, and bilateral pleuroamniotic tubes were then inserted. Caryotype was normal. Soon after birth, she presented with respiratory distress. Repeated bilateral thoracocenteses were performed during the first 11 days with an increasing volume extracted (total volume $1100 \mathrm{ml}$ ). A left sided chest tube was then inserted in order to instil povidone-iodine (Betadine $4 \%$ scrub). The pleural effusion resolved within 48 hours, but increased on the right side. On day 13, a right sided chest tube was therefore inserted and povidone-iodine was instilled. The chylothorax had resolved completely on day 20. Thyroid function tests were normal before and after treatment. This infant is at present healthy.

\section{Case 3}

Macrosomy and hydramnios were observed at 32 weeks in a female fetus. Caryotype was normal. At 36 weeks, a right compressive pleural effusion was noted, and caesarean section was performed immediately. At birth, the first thoracocentesis revealed chylothorax. Initial management consisted of repeated bilateral thoracocenteses. After three weeks, the left pleural effusion had disappeared. However, because of a residual right sided effusion, a chest tube was inserted for six weeks. The maximal daily pleural effusion volume reached $300 \mathrm{ml}$. On day 59, povidoneiodine (Betadine 10\% dermique) was instilled through the chest tube. A rapid recovery was noted six days later, and the chest tube was removed. Blood and urinary iodine levels and thyroid function tests were normal before and after treatment. The infant is alive and well 22 months later.

\section{Case 4}

At 32 weeks gestation, an antenatal diagnosis of left chylothorax was made. It was well tolerated until the appearance of a right effusion at 35 weeks. At 36 weeks, in utero effusion punction was performed because of heart rate 




abnormalities. A chromosome analysis was normal. At birth, bilateral chest tube pleurodesis was performed during the first 6 days of life followed by repeated left thoracocenteses every three days. Because of persistent effusion, a chest tube was inserted again on day 16 on the left side and day 22 on the right side. The daily effusion volume at that time was about 300-350 $\mathrm{ml}$, and the total volume was $2600 \mathrm{ml}$. On day 22 , chemical pleurodesis with povidone-iodine (Betadine $4 \%$ Scrub) through the left chest tube was carried out. The left sided pleural effusion resolved over 48 hours, but a parallel increase in the right sided pleural effusion was observed. Further intrapleural instillations of povidone-iodine (right side on day 25 and left side on day 26) were unsuccessful. The infant developed renal failure, with bilateral candida related thrombosis of the renal veins. He died from end stage renal failure, oliguria, hydrops, and refractory hypotension. An autopsy showed diffuse lymphatic abnormalities with congenital pulmonary lymphangectasis.

\section{DISCUSSION}

In an attempt to decrease the morbidity usually associated with the classical management of congenital chylothorax (infections, thrombosis, deficit in lymphocytes, deficit in proteins and immunoglobulins, complications of total parenteral nutrition, complications of mechanical ventilation), we treated four neonates by intrapleural instillation of povidone-iodine through a chest tube. This procedure was successful in three of the four cases and appeared to be well tolerated. Systemic analgesia was achieved with a morphinomimetic (fentanyl or sufentanyl), as Betadine injection causes pain, and sedation with intravenous midazolam (Hypnovel). No local anaesthesia (such as intrapleural lidocaine) was required. Pain monitoring using the Objective pain scale showed that the systemic analgesia was effective. Breathing was supported by artificial ventilation in all the babies because of respiratory distress.

We used two different versions of the product: Betadine 4\% scrub and Betadine 10\% dermique. This was because the procedures were carried out in two different neonatal intensive care units. Betadine 10\% dermique (used in case 3) was diluted with normal saline $(3 \mathrm{ml}$ Betadine $10 \%$ dermique $+7 \mathrm{ml}$ saline). Betadine $4 \%$ scrub was used without dilution. With both products, the chest tube was cleared after the injection with 10-15 ml normal saline, just before chest tube occlusion. The duration of chest tube occlusion was empirical; it was supposed to be three to five hours.

Improvement occurred progressively, and the tube was removed 6-16 days after the procedure. The most impressive recovery was observed in case 3 , in which the procedure was successful within six days, contrasting with the failure of two months of conservative treatment. However, it may be the natural evolution of this pathology. In fact, from our experiences it is difficult to determine the effectiveness of Betadine in the treatment of congenital idiopathic chylothorax. Usually, the condition resolves in the first few weeks (two to six) with conservative treatment. ${ }^{15}$

Evacuation of pleural fluid can be controlled by either a conservative or a surgical approach. ${ }^{1-6}{ }^{10-12}$ Because of its high success rate $(75-80 \%),{ }^{5}$ it is widely accepted that conservative treatment should be the first option. The point at which conservative treatment should be considered to have failed is not well defined. Some investigators have recommended that surgical treatment should be performed no longer than four weeks after the diagnosis. ${ }^{11}$ In addition, Selles et al. ${ }^{14}$ recommend surgery rather than conservative treatment whenever the daily output of chylous fluid is in excess of $1500 \mathrm{ml}$ in adults or $100 \mathrm{ml}$ per year of age in children for more than five days, or a persistent flow of chyle for two weeks. We decided to administer intrapleural 
Neonatal management of congenital chylothorax

Conservative approach

- Management of underlying disease 256

- Repeated thoracocenteses' 24611

- Continuous drainage 24611

- Dietary modifications (medium chain triacylglycerol diet or total parenteral nutrition) $1-611$

- Chest tube pleurodesis' 2 4-6

- Chemical or mechanical pleurodesis 512

- High positive end expiratory pressure during mechanical ventilation ${ }^{10}$

Surgical approach

- Thoracoscopic pleurodesis ${ }^{2}$ 4-6 12

- Pleuroperitoneal pump $p^{4-6} 1112$

- Surgical abrasion 2512

- Ligation of the thoracic duct (by thoracoscopy or thoracotomy $y^{3-6} 12$

- Thoracic duct to azygous vein anastomosis and lung transplantation (lymphangioleiomyomatosis) ${ }^{6}$

povidone-iodine when surgical abrasion of the pleura was being considered. The latter method is fairly invasive, requires general anaesthesia, and increases the risk of adverse effects such as blood loss and pain. In the past, chemical pleurodesis with talc, bleomycin, or tetracycline has been performed in chylothorax. ${ }^{2}$ However, to our knowledge, the intrapleural injection of povidone-iodine as a chemical agent for pleurodesis in congenital chylothorax has never been reported. This agent has previously been used for the sclerosis of postoperative pelvic lymphoceles ${ }^{15} 16$ and pleural lavage of empyema in adults. ${ }^{17} \mathrm{~A} 100 \%$ success rate has been reported when this agent was administered to 15 adult patients with a malignant pleural effusion. ${ }^{18}$

The mechanism of action of povidone-iodine appears to be related to enhanced sclerosis, ${ }^{15}$ although the precise mode of action remains unclear. Iodine has strong oxidative and cytotoxic properties, which induce a potent inflammatory response in the wall of any fluid containing structure. ${ }^{15}$ Moreover, povidone-iodine may have antiexudative properties related to the chelation of proteins. ${ }^{15}$

As this treatment was new to our unit, we paid careful attention to any adverse effects. The frequent use of topical cutaneous povidone-iodine in neonates can induce allergic sensitisation and impairment of thyroid function. Local cytotoxic mucosal and skin lesions have been described. ${ }^{19}$ The only adverse effect that we considered to be possibly related to the treatment was generalised oedema, which occurred 24 hours after povidone-iodine instillation in case 3. This may have been of allergic origin, although other manifestations of an allergic reaction were not present. Hydrazine (Atarax) was given because of allergy (asthma, skin allergy) in the parents. No cases of anaphylaxis were observed. The contralateral increase in pleural effusion may simply be due to the transfer of fluid through collateral lymphatic vessels in the chest. It led us to suggest that a bilateral procedure should be performed if the chylothorax involves both pleural spaces. The risk of hypothyroidism is theoretically greater after the intrapleural instillation of iodine than after its application to the skin. In the three cases investigated $(1,2$, and 3$)$, thyroid function tests before and after the procedure remained unchanged. Of note, the infant who did not respond to the treatment (case 4) had serious renal involvement before the procedure. Povidoneiodine may have worsened his oligoanuria and end stage renal failure. Necropsy revealed diffuse lymphangectasia involving the lungs and abdomen.

\section{Conclusion}

This report illustrates the feasibility of intrapleural injection of povidone-iodine for the treatment of congenital idiopathic chylothorax. This treatment was administered when the classical management of the disease (nil by mouth, parenteral nutrition, pleural punctures, chest tube drainage) failed, in an attempt to avoid more invasive surgical procedures. Adverse effects were minor (allergic oedema?). A recent study confirms the effectiveness of this treatment for recurrent pleural effusion in adults. ${ }^{20}$ Used early, this method has the potential to reduce the morbidity related to prolonged hospital stay. Use of adequate analgesia is a priority. The present results are not sufficient to assert that the therapeutic regimen proposed is efficacious, and a prospective randomised study in newborns treated with intrapleural povidone-iodine is required.

\section{Authors' affiliations}

O Brissaud, R Mohsen, M Fayon, J L Demarquez, Paediatric and Neonatal Intensive Care Unit, Hôpital Universitaire Pellegrin, Hôpital des enfants, Bordeaux, France

L Desfrere, Neonatal Unit, Hôpital Universitaire Port-Royal, Paris 14, France

Correspondence to: Dr Brissaud, Hôpital Universitaire Pellegrin, Hôpital des enfants, Place Amélie Raba-Léon, 33076 Bordeaux Cedex, France; olivier.brissaud@free.fr

Accepted 14 October 2002

\section{REFERENCES}

1 Al-Tawil K, Ahmed G, Al-Hathal M, et al. Congenital chylothorax. Am J Perinatol 2000;17:121-6.

2 De Beer HGJ, Molet MJT, Janssen JP. Chylothorax. Neth J Med 2000;56:25-31.

3 Dendale J, Comet $P, A$ mram D, et al. Le chylothorax de découverte anténatale. Arch Pediatr 1999;6:867-71.

4 Van Straaten HLM, Gerards U, Krediet TG. Chylothorax in the neonatal period. Eur J Pediatr 1993;152:2-5.

5 Beghetti M, La Scala G, Bugmann P, et al. Etiology and management of pediatric chylothorax. J Pediatr 2000;136:653-8.

6 Romero S. Nontraumatic chylothorax. Curr Opin Pulm Med 2000;6:287-91.

7 Mussat P, Dommergues M, Parat S, et al. Congenital chylothorax with hydrops: postnatal care and outcome following antenatal diagnosis. Acta Paediatr 1995;84:749-55.

8 Fox GF, Challis D, O'Brien KK, et al. Congenital chylothorax in siblings. Acta Paediatr 1998;87:1010-12.

9 Battin MR, Yan J, Aftimos S, et al. Congenital chylothorax in siblings. Br J Obstet Gynaecol 2000;107:1516-17.

10 Ragosta KG, Alfieris G. Chylothorax: a novel therapy. Crit Care Med 2000;28:1208-9.

11 Büttiker V, Fanconi S, Burger R. Chylothorax in children, guidelines for diagnosis and management. Chest 1999;116:682-7.

12 Engum SA, Rescorla FJ, West KW, et al. The use of pleuroperitoneal shunts in the management of persistent chylothorax in infants. J Pediatr Surg 1999;34:286-90.

13 Buettiker V, Hug Ml, Burger R, et al. Somatostatin: a new therapeutic option for the treatment of chylothorax. Intensive Care Med 2001;27:1083-6.

14 Selles JG, Snyder WH, Schreiber JT. Chylothorax: indications for surgery. Ann Surg 1973;177:245-9.

15 Cohan RH, Saeed M, Schwab SJ, et al. Povidone-iodine sclerosis of pelvic lymphoceles: a prospective study. Urol Radiol 1988;10:203-6.

16 Montalvo BM, Yrizarry JM, Casillas VJ, et al. Percutaneous sclerotherapy of lymphoceles related to renal transplantation. J Vasc Interv Radiol 1996;7:117-23.

17 Schutz R, Delclaux C, Balloul-Delclaux E, et al. Traitement des pyothorax et pyopneumothorax d'origine infectieuse d'évolution chronique par drainage-lavage à la polyvinylpyrrolidone iodée. Rev Mal Respir 1992;9:313-17.

18 Echavarria A, Pinzon V, Bares JP, et al. Intracavitary treatment of malignant pleural effusion with iodine-povidone. Rev Med Panama 1991;16:69-74.

19 Ancona A, Suarez de la Torre R, Macotela E. Allergic contact dermatitis from povidone-iodine. Contact Dermatitis 1985;13:66-8.

20 Olivares-Torres CA, Laniado-Laborin R, Chavez-Garcia C, et al. lodopovidone pleurodesis for recurrent pleural effusions. Chest 2002;122:581-3. 